\title{
DEVELOPMENT OF A PROTOTYPE TEST RIG FOR A CRYOGENIC, MARINE, HEAVY LIFT, BUOYANCY SYSTEM
}

\author{
R. F. Nicholls-Lee \\ University of Southampton \\ Southampton, Hampshire, U.K.
}

\author{
S. R. Turnock \\ University of Southampton \\ Southampton, Hampshire, U.K.
}

\author{
M. Tan \\ University of Southampton \\ Southampton, Hampshire, U.K.
}

\author{
P. C. McDonald \\ University of Southampton \\ Southampton, Hampshire, U.K.
}

\author{
R. A. Shenoi \\ University of Southampton \\ Southampton, Hampshire, U.K.
}

\begin{abstract}
There is a continual search for new methods of marine salvage and decommissioning of structures in the open sea in order to improve control and lower operational costs. The concept design of a lightweight, cryogenic, marine, heavy lift, buoyancy system has been investigated. The objective is to be able to raise or lower high mass objects controlled solely from a surface support vessel. The overall design concept and associated system development issues have been discussed previously. This work concentrates on the development of a test rig for the cryogenic, marine, heavy lift, buoyancy system and associated test procedures. The main area of concern in the design process is the cryogenic Dewar. This is required to operate at temperatures as low as $-196^{\circ} \mathrm{C}$ but also at pressures exceeding 35bar. A more detailed design of the Dewar, including cryogenic composite materials testing, is considered. The prototype will be assessed through three different testing scenarios; shallow water, open water deep sea, and a hyperbaric chamber for very high pressure testing. The procedures for each of these test scenarios is discussed.
\end{abstract}

Keywords:- composite, control, cryogenic, heavy lift, marine salvage, offshore decommissioning.

\section{INTRODUCTION}

Numerous methods of lifting and lowering objects from the seabed have been developed throughout the history of ocean engineering and exploration [1]. The methods more commonly used today include cranes and lift bags and an assortment of Remotely Operated Vehicles (ROVs). Cranes are popular for deep water lifts, and are used to depths of $2000 \mathrm{~m}$, however there are problems. Cable weight increases with depth, to a point at which it becomes much greater than that of the payload for deeper lifts. The sea state in which lifts can take place is limited due to the motion of the vessel on which the crane is mounted; this then leads to constraints because of predicted weather windows. Lastly there is the large cost of hiring the vessels and their often limited availability. In the case of lift bags control, or rather lack of, is the governing factor. The bags release excess air from the open bottom as they ascend. There are enclosed lift bags that have a limited capacity to dump air through pressure release valves; however, ascent rate is still fast. The rate of ascent is coarsely controlled by adding more weight to the bags, and the slow steady ascent required for structurally unsound objects is difficult to achieve. ROVs are highly controllable, and have been designed to cope with the extremely high pressures at deep depths (in excess of $6000 \mathrm{~m}$ ). They are, however, complex and expensive systems and require power supplied by means of an umbilical for operation. As such, the mass that these vehicles can lift is limited by the size and power of the thrusters which are used for propulsion.

Consequently there is an industrial need to develop new concepts for the salvage and decommissioning of offshore structures, and also for installation of new structures. These designs must be capable of relatively remote operation, safe, cost effective and environmentally responsible, with high levels of control. As such they are able to overcome the problems associated with current launching and recovery apparatus. Even with new concepts that have been generated there are significant problems that need to be overcome. The Controlled Variable Buoyancy System (CVBS), for example, was unsuccessful due to the low lifting load of each individual unit 
which meant that many were required for one lift, each requiring a complex arrangement of umbilicals and many air compressors for operation. The surface support vessels could also be moored no nearer than one mile away causing these umbilicals to become long and the whole system very complex [2].

The concept design of a lightweight cryogenic marine heavy lift buoyancy system has previously been investigated [3]. The objective was to be able to lift or lower large displacement objects under full remote control. The nature of subsea lifting and lowering operations requires a high degree of precise control for operational safety, reasons and to preserve the structural integrity of the load. The lift operation occurs in two phases: development of lift to overcome seabed suction, and then rapid reduction of buoyancy to maintain a controlled ascent. Descent involves controlled release of the buoyancy. The proposed buoyancy system consists of a buoyancy chamber and an integral cryogenic gas generation unit. The application of an on-board gas generation unit allows the removal of the engineering challenges associated with use of compressors and the concomitant complex manifold of connecting umbilical pipe work. It provides for a fully remote system completely eliminating all risk associated with extensive physical surface to subsea connection throughout the entire lift operation.

The opening stages of the project work included the development of a system that operates efficiently and effectively to a depth of $350 \mathrm{~m}$. An initial general arrangement for the buoyancy system was developed. As part of the design process for such an arrangement, numerical simulation of the complete system was undertaken in order to develop mechanical, cryogenic and process control systems efficiently and effectively. This system simulation has been developed using Matlab Simulink, the initial stages of which were discussed previously [3]. The paper considered the overall design concept and associated system development issues. These were illustrated through use of the time accurate simulation of alternative design configurations that confirmed the viability of the concept.

This work concentrates on the development of a test rig for the cryogenic, marine, heavy lift, buoyancy system and associated test procedures.

A number of the sub-systems in one complete buoyancy system involve considerable design and development, these include: structural design of the buoyancy chamber, mechanical systems to control and connection to the lift device, the cryogenic system itself and overall process control systems. The main area of concern in the design process is the cryogenic Dewar. This is required to operate not only at temperatures as low as $-196^{\circ} \mathrm{C}$ but also to withstand pressure differences exceeding 35bar. The design and manufacture of the Dewar is a major undertaking. A more detailed design of the Dewar, including cryogenic composite materials testing, is considered. Several methods of gasification are presented, with advantages and disadvantages discussed.
There are several stages of testing the prototype will be required to undertake, with increasing levels of severity and realism. These operations are discussed and conclusions made with regards to the relevancy of the test to the overall end use and also the applicability of the buoyancy system for commercial operation.

\section{THE CRYOGENIC DEWAR}

The DSR (Deep Sea Recovery) buoyancy system has a modular design such that components can be replaced/upgraded without having to construct an entirely new vessel. The modularity also enables the system to be transported more easily. Figure 1 illustrates a schematic of the DSR buoyancy system

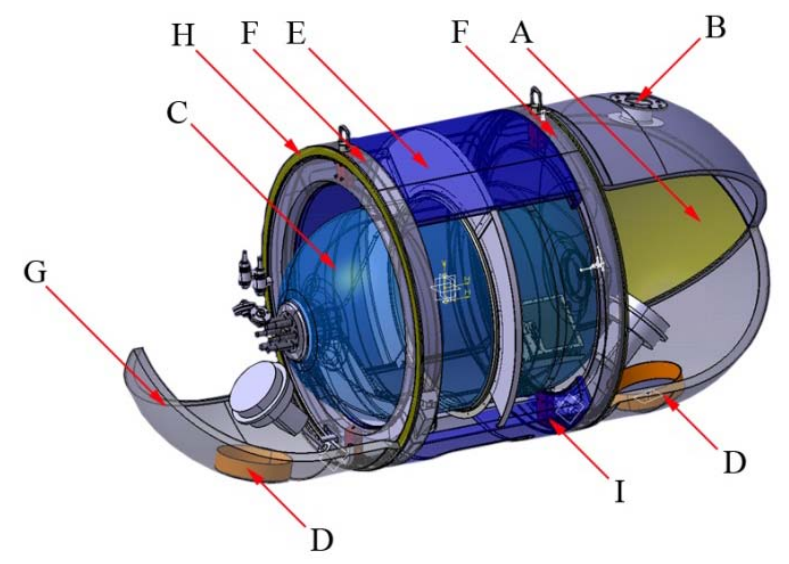

Figure 1: General arrangement of the buoyancy system

where:

A. Buoyancy chamber - one at either end of the caisson.

B. Main valves - one in the top of each buoyancy chamber.

C. Cryogenic Dewar.

D. Free flood vents.

E. Central membrane dividing the buoyancy chambers

F. Two structural rings approx $1 \mathrm{~m}$ apart giving two lifting attachment points.

G. Caisson shells in four segments with a bonded assembly. Flanges add stiffness to structure.

H. O-ring face seal between structural rings and end shells.

I. Dewar is support by brackets bolted to structural ring and has a compliant interface.

The central part of the buoyancy device (C) is the cryogenic Dewar. The Dewar holds liquid nitrogen (LIN) at $-196^{\circ} \mathrm{C}$ and ambient pressure. The cryogen is heated to produce Nitrogen gas at the ambient temperature and pressure which is then released into the buoyancy chambers. This gasification process also provides a measure of buoyancy control alongside that of the top valves (B). The Dewar is shorter and broader than conventional containers, with the axis parallel to that of the caisson. This results in the stronger domed ends providing 
much more effective structural support than in a conventional configuration.

\section{Dewar Design}

The Dewar is required to carry a volume of LIN to a depth of $350 \mathrm{~m}$. At an absolute minimum it will be required to operate at pressures exceeding 35bar and temperatures down to $-196^{\circ} \mathrm{C}$. It consists of an inner chamber which contains the LIN, a vacuum cavity for insulation, and an outer skin which must withstand the ambient pressure. In the event that the buoyancy system is inadvertently taken to a depth exceeding $350 \mathrm{~m}$, for example on an uneven seabed, the design pressure has been taken to be 40 bar $(400 \mathrm{~m})$.

Figure 2 shows the Dewar without the caisson. It is formed of a two part carbon outer casing enclosing the steel lined, fiberglass wrapped inner container.

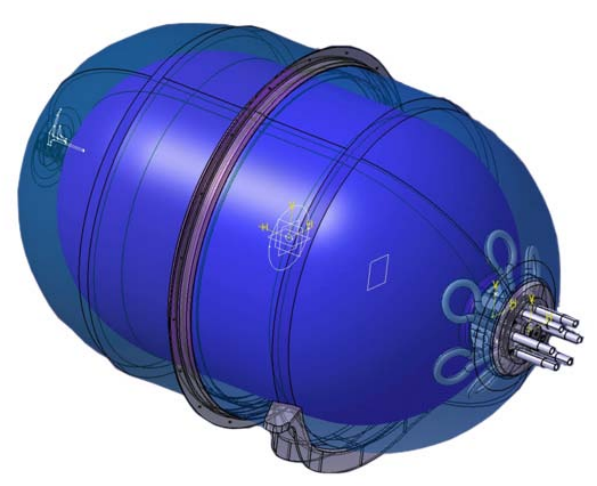

Figure 2: The Dewar

The LIN will boil off slowly while the caisson is stationary, consequently building up pressure inside the Dewar. It is thought that the most feasible method of removing the LIN from the Dewar for gasification is simply to allow the pressure to build up in the inner chamber to a point at which it is greater than the ambient pressure and the LIN is forced out. This is achieved both through LIN boil off and a pressure build circuit. Therefore, while the outer chamber of the Dewar must be able to withstand up to 40 bar external pressure, the inner chamber will be required to operate at internal pressures in excess of this. As such both chambers require considerable structural design.

The Dewar is designed using ASME Section X Class 1 design - 'qualification of a pressure vessel design through the pressure testing of a prototype'. While these rules do not make provision for the design of a composite, cryogenic pressure vessel operating in the deep sea (the minimum vessel operating temperature is $-54^{\circ} \mathrm{C}$ ), they do provide a design guide as to operational safety factors. The Section $\mathrm{X}$ rules require pressure testing at five times the design pressure, for a vessel with polar boss openings along with fatigue testing to design pressure for 33000 cycles. It is also useful to note that the maximum pressure for filament wound vessels with polar boss openings is 3000 psi. As such it has been decided that the safety factor for the inner vessel of the Dewar will be five times the design pressure plus 20\%. The outer vessel, however, will be have a safety factor of five to a depth of $100 \mathrm{~m}$ and then a safety factor of two to a depth of $350 \mathrm{~m}$. This is because the risk of a system failure at deeper depths causing injury to humans is negligible, especially with the control vessel being positioned some distance from the lift site. The most likely failure mode of the Dewar is illustrated in Figure 3.

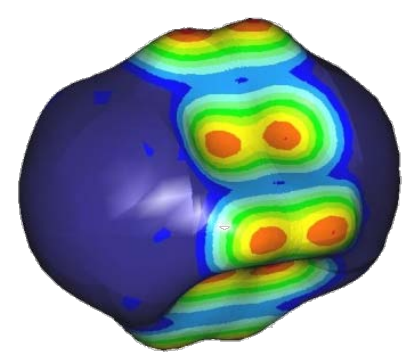

Figure 3: The failure mode of the Dewar evaluated using the FEA package Nastran

One of the main factors governing the whole buoyancy system is the overall system mass; the lighter the system, for a fixed volume in the buoyancy chambers, the larger the payload that may be lifted. One area in which much mass can be saved is the Dewar. Conventional Dewars are constructed of stainless steel which, in order to withstand the pressures that the system is to operate at, would need to be very thick. Instead the inner vessel of the Dewar is to be made out of S2 fiberglass wound over a thin steel liner. The liner not only acts as a mandrel, but also prevents gas seeping through the composite layers, making the inner vessel a Composite Overwrapped Pressure Vessel (COPV). It should be noted, however, that the liner is not an integral structural part of the Dewar and the inner vessel would still have a safety factor of five without it. The fiberglass overwrap is to be placed using Automated Fiber Placement (AFP) which ensures that the fibers are located in an optimal arrangement to spread the load distribution, therefore minimizing the amount of material required. The coefficient of thermal expansion of the S2 fiberglass and resin is relatively similar, meaning that when LIN is introduced to the steel liner it should not shrink a large amount compared to the overwrap, minimizing any possible gap.

The outer vessel of the Dewar must withstand a large compressive pressure which composite materials are not generally suited to; however, it has been found that the use of T700 carbon fiber pre-preg at a thickness of $14 \mathrm{~mm}$ through the middle section and $10 \mathrm{~mm}$ at the hemispherical ends provides the required strength without the need for an inner liner. This reduces the mass of the vessel by several hundred kilograms. The thickness discrepancy between the ends and middle of the outer vessel is due to the inherent stability of the hemispherical shape when compared to the cylindrical mid-section under external pressure loading. The structure has polar boss openings at both ends for the pipe work for filling and emptying, safety release valves and the pressure build system. 


\section{Dewar Testing}

With the Dewar operating at temperatures as low as $-196^{\circ} \mathrm{C}$, and parts of it in contact with the LIN, thorough testing of components and the whole entity is essential. The steel liner is to be constructed by a company specializing in cryogenic Dewars from standard materials and as such does not require coupon testing. The composite materials, however, have not been used as part of a cryogenic system before and therefore a series of tests have been proposed in order to qualify the materials for use in the Dewar construction.

Initially coupons of the specific materials were provided and tested at room temperature and pressure at the University of Southampton. These tests comprised of both static and cyclic tensile tests. The results of these tests were to provide a basis of comparison for the tests of specimens at lower temperatures. The next stage involved testing some specimens at a low temperature in an insulated chamber, Figure 4.

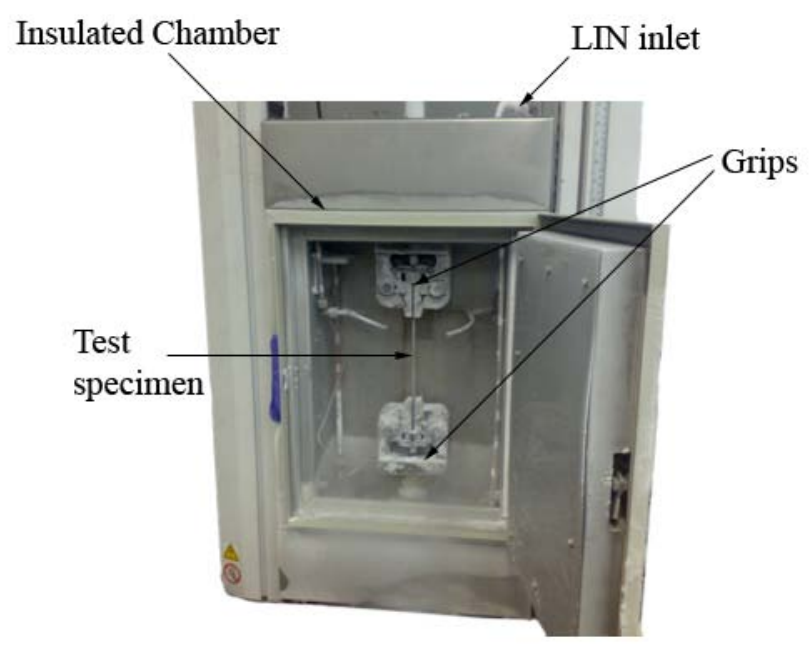

Figure 4:Initial cryogenic test setup

This system was limited in that the lowest temperature that could be reached was around $-165^{\circ} \mathrm{C}$, over $30^{\circ} \mathrm{C}$ warmer than the Dewar will be subjected to. Problems were also encountered with the specimen grips at these low temperatures. To start with a group of specimens were simply placed in the insulated chamber, none in the grips, and the whole system cooled to as low a temperature as possible. Once a suitable temperature had been reached the intention was to place a cold specimen in the grips and carry out the tests. This method has the advantage of time, insofar as all of the specimens are already cold before testing. At the very low temperatures, however, the grips had seized up and therefore a sample could not be fitted into them. The system was allowed to thaw, a single specimen placed in the grips, and then the whole system re-cooled. This was an incredibly time consuming method of testing as it involves the entire test setup being cyclically thawed and chilled for each individual specimen. Three tests were carried out using this method at a temperature of $-165^{\circ} \mathrm{C}$.
Of these three tests one specimen failed at the end tabs and the other two slipped out of the grips. The specimen that failed at the end tabs failed at a load of $24 \mathrm{kN}$; this compared well to the room temperatures tests which all failed near a load of $25 \mathrm{kN}$. A single test is not enough to make design decisions on and as, in retrospect the jaw grips are not suitable for such low temperature testing, and a new test setup has been proposed.

The new setup makes use of specimens with holes in the end such that they can be pinned in place in an insulated container. A further benefit is that the specimens will be tested whilst submerged in LIN, and hence at a temperature of $-196^{\circ} \mathrm{C}$. A schematic of the experimental setup is illustrated in Figure 5.

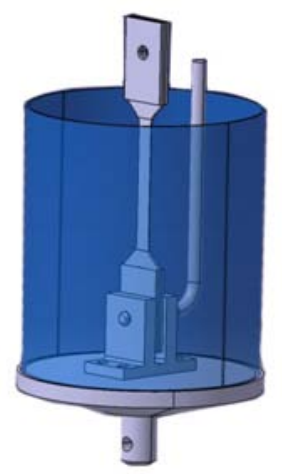

Figure 5: Experimental setup for tests fully submerged in LIN

The specimen is inserted in the top of the chamber, with a long handled pin put through the lower hole for ease of setup. The top of the specimen is also attached and the chamber surrounding the specimen filled with LIN. The LIN is in continuous supply so that the specimen is constantly submerged throughout testing. The system is allowed to cool and then testing is carried out in the normal manner.

Subsequent to successful coupon testing at a small scale, it is intended that a scale prototype of the inner vessel of the Dewar be constructed and tested. Figure 6 shows a model of the test inner chamber.

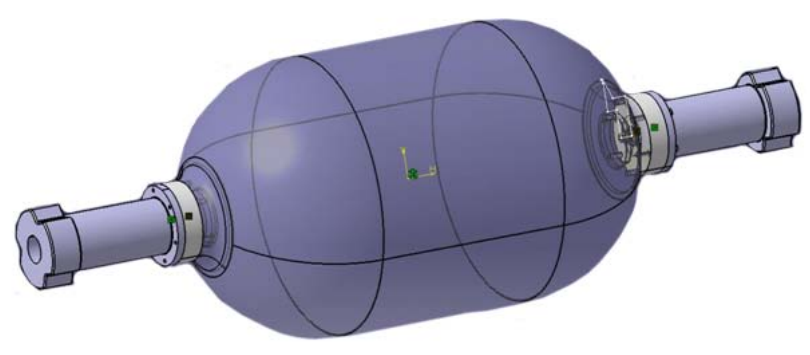

Figure 6: Scale inner vessel test specimen

It is intended that this vessel be constructed in the same manner as the full scale inner vessel, with a stainless steel liner and fiberglass overwrap. It will be fitted with instruments, and 
tested to destruction by increasing the internal pressure to a point significantly beyond the design pressure. The performance at increased pressures will be noted, as will the manner of failure.

A major concern regarding the Dewar design and classification were the safety relief valves. In an ordinary Dewar these valves are designed to relieve any over pressure, above that which has been designed, however have not been considered for subsea usage. In the DSR buoyancy system the valves will be enclosed by the buoyancy chambers, but it is not guaranteed that they will be in a gaseous environment - it depends at what level of gas/sea water is in the buoyancy chambers. If the valves are blocked by ice, there is a risk that the Dewar may over pressurize, and ultimately explode. If this occurred in the deep sea it is of less significance, the main result being a failure of the system; however if it occurred at or near the surface it could cause damage to the support vessel, or personnel. As such it was felt that this was an area that required further investigation and testing of the cryogenic pressure relief valves in water at pressures equating to shallow water depths. Figure 7 illustrates the experimental setup for the relief valve tests.

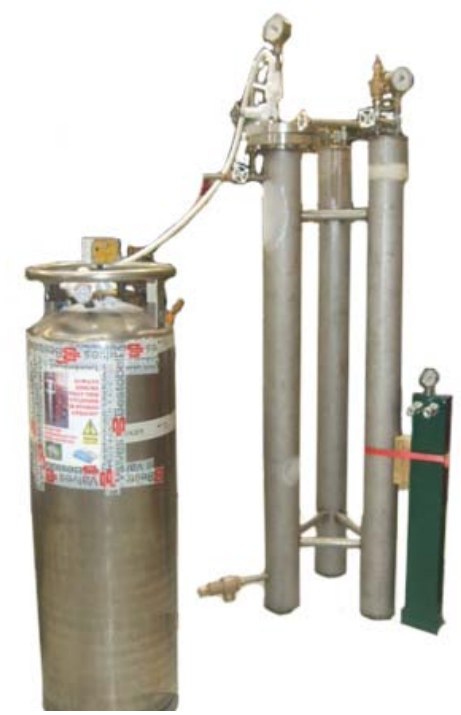

Figure 7: Experimental setup for the testing of a cryogenic relief valve

The main pressure chamber consists of three $150 \mathrm{~mm}$ diameter tubes connected towards the top and base of each one. The assembly is half filled with water. The test rig has a 200 liter LIN Dewar connected to a safety valve inlet at the top of the tri-tube assembly. The safety valve on test is located in the left-hand tube of the assembly, $0.6 \mathrm{~m}$ below the water surface. There is a further relief valve on the top of the right hand tube which releases nitrogen gas and provides control of the pressure inside the system.

Initially the LIN was released in to the system at a pressure of 4.5bar, with the safety valve under test set at 2.5 bar, this results in a 2 bar difference. The system relief valve was set at
2 bar causing a 2 bar back pressure to simulate depth (20m). After the LIN had been flowing for 30 minutes the inlet line was observed to have frosted up. There was also ice forming on the outside of the pipe in which the test valve was located, where the test valve was situated, Figure 8.

For ice to form on the outside of the pipe, the temperature on the inside must be below zero, therefore indicating that ice has formed in the water around the test valve. Despite this the valve still operated effectively, shutting off when the pressure was reduced below its rated value. After an hour of LIN discharge at 4.5bar ice was observed to have formed on the outside of the pipe above the surface of the water suggesting that the gas inside is at a subzero temperature. At this point in the test the safety valve was still operating.

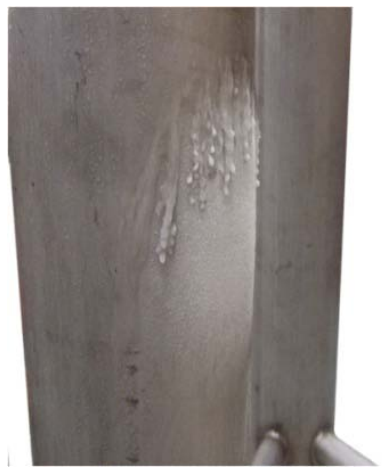

Figure 8: Ice accretion on the outside of the pipe by the test valve

The back pressure in the system was then increased to 7.5 bar $(75 \mathrm{~m})$ to observe the effect of increasing pressure at depth. After 10 minutes the water temperature had decreased from $10^{\circ} \mathrm{C}$ to $1.5^{\circ} \mathrm{C}$. One hour into the test the temperature measured had decreased to $-126.7^{\circ} \mathrm{C}$. The safety valve was still discharging at this point, but would not fully close and nitrogen was heard to be bubbling out when an attempt to shut it off was made. Ice had formed around the safety valve and the flow of nitrogen through the ice was preventing the remaining water contacting the area; indicated by the low temperature at this point. It should be noted that the temperature is above freezing both above and below this point on the test rig. This shows that while the valve could not be shut off, neither would the system explode thus decreasing the risk of injury of personnel. The worst case scenario is that there is not enough gas left in the buoyancy system, in both the Dewar and the buoyancy chambers, to enable the system to surface and be recovered.

The limitation of this test rig is that it only holds $75 \mathrm{~kg}$ of water whereas in the sea the water, and hence heat available, is effectively unlimited and icing around the valve would be very unlikely when the test results are considered and extrapolated.

\section{Gasification}

The gasification of the LIN is a major process in the operation of the DSR buoyancy chamber. The nitrogen gas produced is used to create the buoyancy, and hence lift, for the 
vessel. It is also a measure of control of the rate of ascent, or decent, of the lifting, or lowering, operation. Since the system is to be provided with power through the use of a non-load bearing umbilical, it was initially thought that a high powered heating element could be used to create gas directly in the Dewar, to be released though a relief valve set slightly above the ambient pressure. Due to power restrictions for the open water tests of the buoyancy system, however, this was not possible and therefore alternative means of gasification were investigated.

As the LIN is at a temperature of $-196^{\circ} \mathrm{C}$ and the seawater significantly warmer, one solution considered was to use a heat exchanger - taking the warmth from the sea and using it to gasify the LIN. The main problem with this concept is that sea water freezes at around $-2^{\circ} \mathrm{C}$ (depending upon the salinity) and therefore a direct transfer from the water to LIN would, most likely, resulting in icing. This would block the heat exchanger, and may also cause problems if ice were to form in the buoyancy chambers which could interfere with the top valves, hence gas release and buoyancy control.

It is thought that a shell and tube heat exchanger would be the most appropriate for use in the DSR buoyancy system. It is the most common type of heat exchanger in oil refineries and other large chemical processes, and is suited for higher-pressure applications (in excess of 30 bar). As its name implies, this type of heat exchanger consists of a shell with a bundle of tubes inside it. One fluid runs through the tubes, and another fluid flows over the tubes (through the shell) to transfer heat between the two fluids. The set of tubes is called a tube bundle, and may be composed by several types of tubes: plain, longitudinally finned, etc.

Two fluids, of different starting temperatures, flow through the heat exchanger. In this case the LIN flows through the tubes and the glycol flows outside the tubes but inside the shell. Heat is transferred from one fluid to the other through the tube walls, either from tube side to shell side or vice versa. In order to transfer heat efficiently, a large heat transfer area should be used, leading to the use of many tubes - however it is important to consider the pressure losses associated with fluid travel along a pipe. In the case of the DSR heat exchanger, the fluid in the shell will not pass through it as in more conventional heat exchangers, rather a heating element near the bottom of the shell will heat the glycol which will circulate due to convection.

Phase change heat exchangers can be used to cool a vapor to a liquid or boil a liquid to a gas. The phase change normally happens on the shell side of the heat exchanger but in the case of the DSR system it will occur in the tubes in order to maintain the high pressure required for the release of the $\mathrm{N}_{2}$ gas into the buoyancy chambers.

It should be noted that shell and tube heat exchangers, whilst being the most suitable for high pressure applications, are also the least efficient - around 60-80\%. Figure 9 illustrates a simple schematic of the heat exchanger situated within the vacuum cavity of the Dewar assembly, and how the LIN will be pressurized and forced through the system.

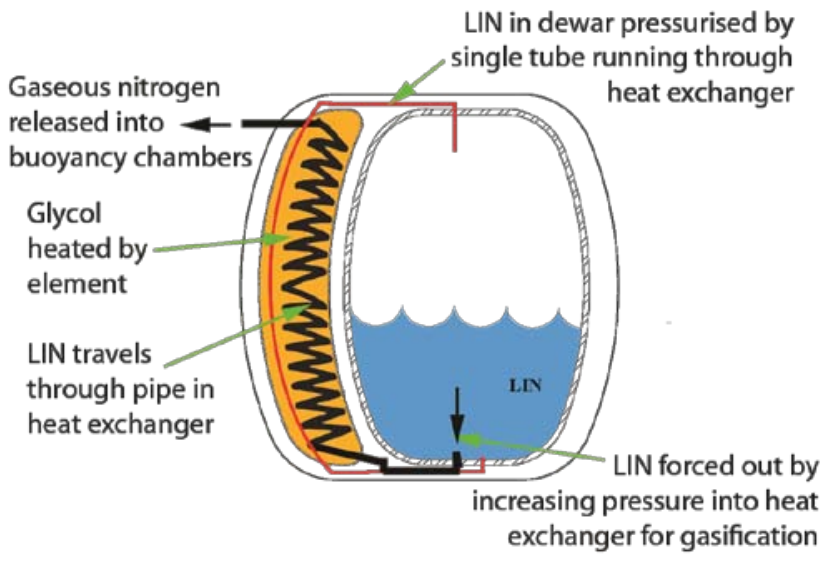

Figure 9: Basic schematic of the heat exchanger in the Dewar assembly

Due to this other varieties of heat exchanger were investigated. Vahterus [4] use a heat exchanger design which combines the benefits of both plate heat exchangers, and shell and tube heat exchangers. This enables the vessels to be compact, low fouling, and have no gaskets, and also capable of coping with high temperatures and high pressures (up to 60 bar). The plates packs are formed by welding two single plates together to make a pair such that the ridges form a gap between them, then several pairs are welded together to make a pack. This is illustrated in Figure 10.

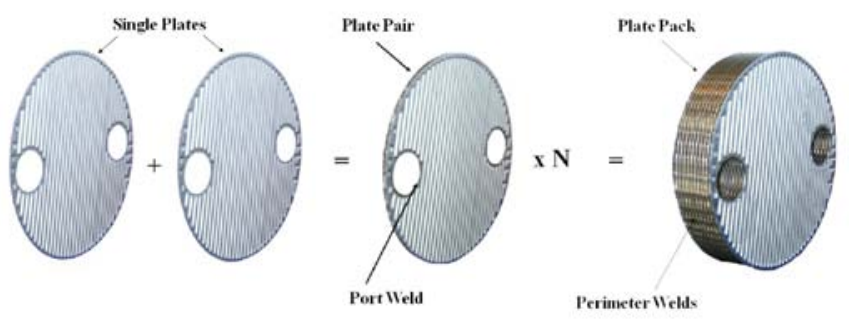

Figure 10: Plate pack structure

The plate packs are then encased in a shell with four ports. Two for the plate side flow, and two for the shell side flow. The plate configuration means that two fluids can pass through alternate plates and thus heat is exchanged very efficiently, Figure 11.

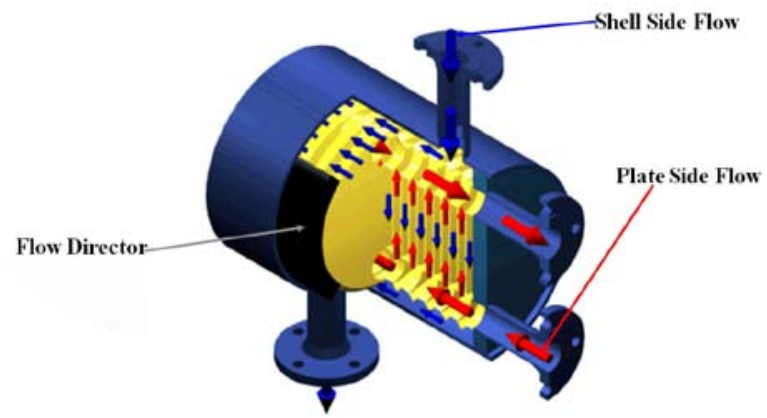

Figure 11: View through the Vahterus heat exchanger - the two flows are separated by the welds 
It was thought that a sufficiently high flow rate of seawater - such that it would not freeze when travelling through the plate pairs adjacent to those filled with LIN - would not be achievable so the use of a thermal oil was considered. Thermal oils have a range of operating temperatures and are designed to be an efficient heat transfer medium for use in certain circumstances where water (for example) may not be appropriate. As such, an arrangement of two heat exchangers was considered; where thermal oil is the "bridging" heat transfer fluid between the LIN and the seawater, thus removing the possibility of the sea water freezing in the heat exchanger. Essentially the seawater would be pumped through one side of the first exchanger, warming the thermal oil passing through the other side, the thermal oil would them be pumped directly into one side of a second heat exchanger in order to warm the LIN.

The LIN flow rate was so determined that it could fill both of the buoyancy chambers of a single caisson in two hours. It was found that an additional heat exchanger to heat the $\mathrm{N}_{2}$ gas to near the ambient seawater temperature would be required; this is referred to as the $\mathrm{N}_{2}$ superheater.

Concerns were apparent, however, as to the viscosity of the low temperature thermal oils at $77 \mathrm{~K}\left(-196^{\circ} \mathrm{C}\right)$. There are few low temperature thermal oils around, the most extreme of which operate down to $173 \mathrm{~K}\left(-100^{\circ} \mathrm{C}\right)$. It was apparent that, at the operating temperatures in the LIN heat exchanger, the thermal oil would be too viscous to flow through the plate pack effectively. Also once it was returned to the sea water exchanger for warming it may be cool enough cause some ice build up and hence blockage. In order to avoid the ice build up only part of the warm oil leaving the seawater heat exchanger would be used to heat the LIN. The rest would be co-mingled with the returning "cold" oil thus raising the temperature enough to avoid icing. Another governing factor in the use of the Vahterus heat exchanger is the weight of the system. Each of the three separate heat exchangers was estimated at between 200-250kg, making an all up weight for one caisson of around $750 \mathrm{~kg}$. This extra mass considerably reduces the size of the payload the buoyancy system can lift and is therefore disadvantageous to operation.

Another type of heat exchanger was considered for use as the LIN gasifier in order to overcome the viscosity issues. This is a Heliflow shell and tube heat exchanger [5]. The Heliflow Heat Exchanger encompasses a spiral coil, comprised of multiple parallel tubes mounted within a casing. The case/coil construction creates a spiral flow path providing true counterflow. It is capable of handling high pressure, specialized materials, cyclic operation, and temperature extremes. Figure 12 shows a cross section of the Heliflow. In the case of the DSR buoyancy system the LIN would pass through the tubes and the thermal oil would be pumped through the shell.

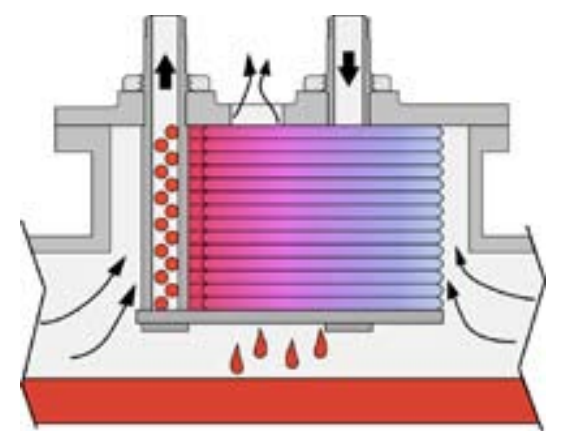

Figure 12: Heliflow heat exchanger

It was apparent, however, that at the oil flow rate illustrated in Figure $12(299 \mathrm{~kg} / \mathrm{hr})$ would cause the thermal oil to be too viscous to operate effectively in the Heliflow, though a higher flow rate resulting in a lesser temperature drop of the oil would solve this problem.

\section{BUOYANCY SYSTEM TESTING}

With the DSR buoyancy system intended for commercial use it is imperative that a prototype be constructed and thoroughly tested. The testing is to be undertaken in three stages; shallow water tests, open water deep sea trials, and pressure testing in a hyperbaric chamber.

\section{Shallow Water Tests}

At sea, control of the buoyancy system will be more difficult at shallow depths; combined with more severe consequences should anything go wrong. Therefore shallow water tests are essential to test the prototype complete buoyancy system in order to confirm that it operates as designed and also in order to iron out any problems prior to offshore, deep water tests.

It is intended that two caissons will be tested in parallel such that the control of one master and a slave system can be demonstrated. The payload is to be in the form of a skid, on which the two caissons are mounted. This enables the load to be of a known, uniform mass. If the stiction force was greater than the lift capacity of the caissons on the skid then the system would not leave the ground, and would not prove to be a beneficial test. Therefore the base of the skid has been designed such that it has a low stiction force, hence significantly reducing the risk of unproductive testing.

The skid is illustrated in Figure 13. Alongside the propensity towards a low stiction force, it includes a drip tray under each Dewar so that any spillage or excess drained will not damage the surface the skid is resting on. Containing any excess LIN also prevents ice forming on the ground around the system and hence the risk of accidents to personnel. 


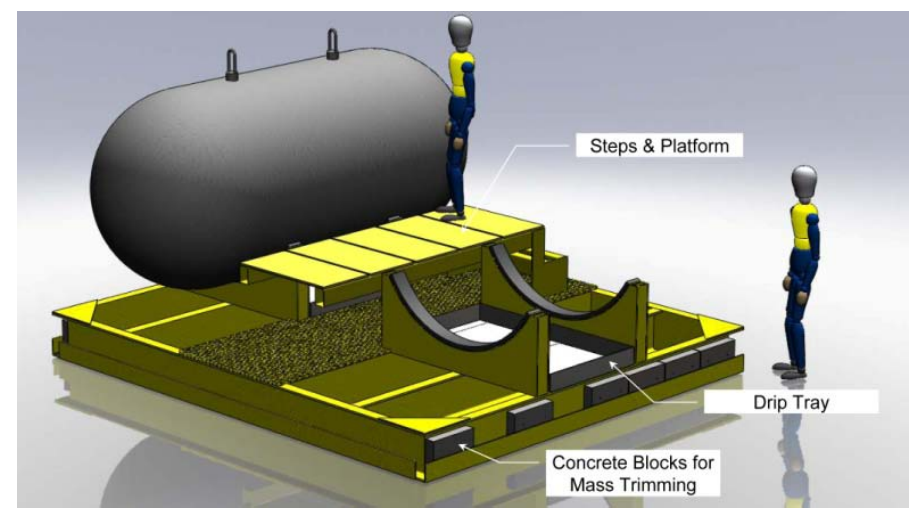

Figure 13: Shallow water test skid

The central platform, reached by steps, creates an area from which the two caissons can be accessed easily. Capacity has been made around the edge of the skid for concrete blocks which act as removable ballast if required. Both caissons rest on two supports and are attached to load cells such that the lift generated can be measured as well as observed, when the system lifts off the ground.

These initial tests are to take place in a flooded quarry, with a maximum depth of over $35 \mathrm{~m}$, with a crane onsite for launch and recovery. This test bed provides easy access to the assembly should alterations be required.

\section{Offshore Deep Water Trials}

The offshore trials have been considered in the form of two scenarios:

1. An idealized test sequence, assuming safe and accurate control of altitude and attitude.

2. A test sequence assuming a 'tethered' test assembly

Both of the test sequences have as one of their principal aims the philosophy of proving the system's ability to control its altitude 'independently'. An alternative third approach, for which a separate test sequence is not presented, is for the subsea test unit to be negatively-buoyant at maximum lift. The disadvantage of a negatively-buoyant configuration is that it requires constant vertical thrust from the ROV to achieve lift. The advantage is that it removes any risk of an uncontrolled ascent.

Idealized Sequence - The following sequence, illustrated schematically by Figure 14, assumes the availability of a single work-class ROV (WROV). The DSR buoyancy system is launched by a deck crane and lowered to the ocean floor. At this stage the system is without power. The WROV docks with the skid, and provides power to the system via a hot-stab. The WROV is neutrally buoyant and therefore does not interfere with the testing of the buoyancy systems. Initially seabed stiction is overcome and the system is demonstrated to be able to dump the excess gas required to do this and then control the attitude of the assembly. Once the system is deemed to be stable tests for roll and pitch are undertaken. These occur by filling one caisson more than the other (roll) or filling one end buoyancy tank of each caisson (pitch). Once these tests are completed satisfactorily, the system is made buoyant and raised to a shallower depth where the test procedure is repeated.

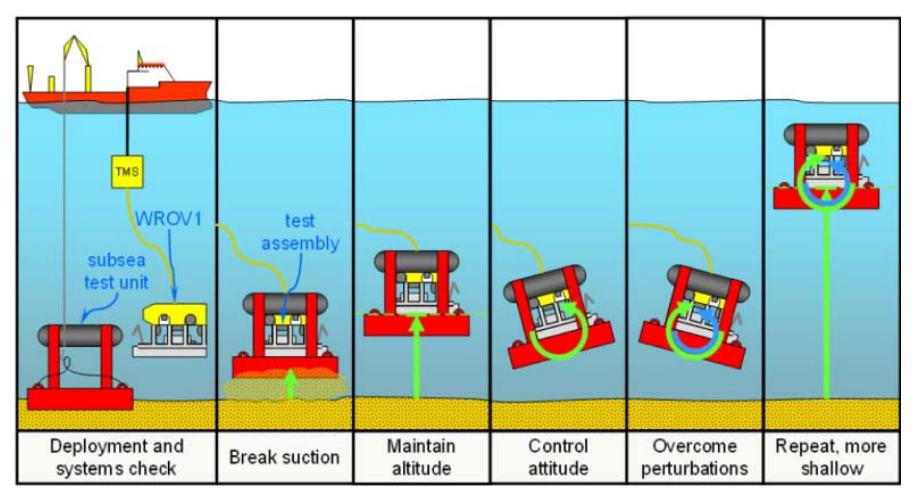

Figure 14: Ideal scenario for offshore trials

The use of a tether may be beneficial for the following reasons:

- Restriction of vertical excursion in the event of an uncontrolled buoyant ascent (preventing the test assembly damaging itself and the vessel).

- $\quad$ Restriction of lateral excursion in the event of unplanned undocking (preventing the subsea test unit drifting away).

- Allows the mass of the subsea test unit to be 'undersized', so that additional lift (over-capacity) can be used to overcome effects such as inertia (including entrained and added mass), drag and seabed suction.

Table 1 addresses options for a tether.

\section{Table 1: Tether Options}

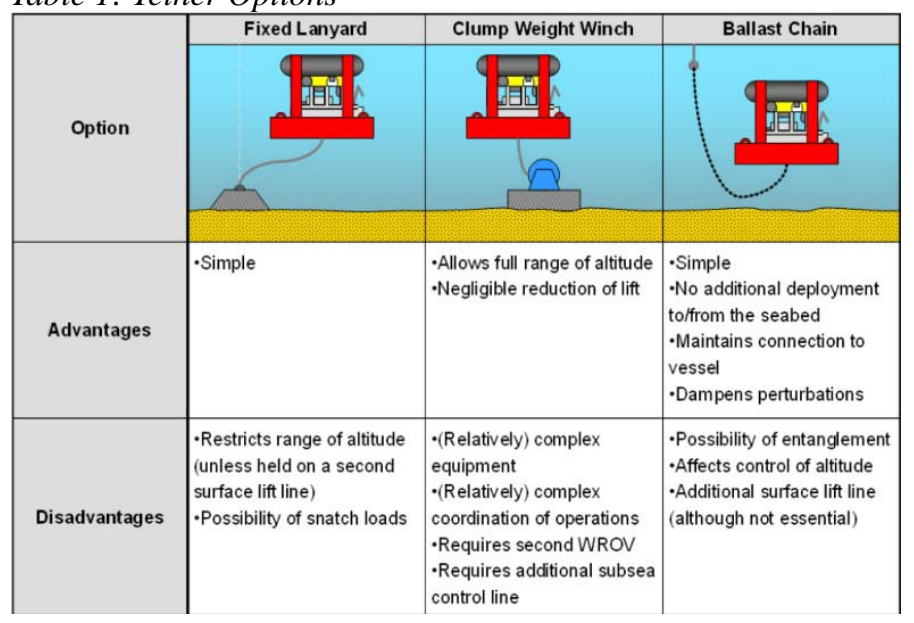

\section{Pressure Testing}

In the event offshore trials are unable to be completed or are not at the required depth of $350 \mathrm{~m}$, testing of the system in a hyperbaric chamber is to be carried out. It is thought that, due to safety measures, just the Dewar assembly will be pressure tested to 35 bar. This will prove that the concept is viable and gas, and therefore buoyancy, can be produced at the required depth. The control systems will have been proven in either/both the shallow water and offshore trials, and will be 
rated far in excess of 35bar, and as such further testing of this area is not required.

\section{CONCLUSIONS}

Further developments for a lightweight composite, cryogenic, marine heavy lift buoyancy system have been discussed.

The Dewar is to be constructed from composite materials in the whole, apart from a thin steel liner in the inner vessel which acts as a mandrel for construction and decreases the gas permeability of the vessel. The use of composite materials in this area has shown considerable weight savings. Initial cryogenic coupon testing showed positive results, however the technique had several flaws and a new method for fully submerged coupon testing at $-196^{\circ} \mathrm{C}$ was proposed. A scale model of the inner vessel of the Dewar has been constructed and will be tested to destruction and the performance analyzed.

The cryogenic safety relief valves have been tested, after concerns that ice accretion may prevent operation. The tests were successful insofar as even with ice accretion the valve still releases pressure thus reducing the risk of catastrophic failure of the Dewar. The valve, however, failed to close after large amounts of icing had occurred and therefore gas would leak out constantly if this situation were to happen.

Due to a limited power supply, the initial concept of using a high powered electric heater to gasify the LIN was not possible. Several different types of heat exchangers have been considered and discussed.

Final testing of the DSR buoyancy system has been considered. Shallow water tests are to be undertaken in a flooded quarry with significant shore support. These tests will prove the system and provide opportunity to solve any problems. Subsequently open water trials are to be carried out from a vessel in deep waters. If the water depth in the open water trials is not great enough to meet requirements $(350 \mathrm{~m})$ then pressure testing of the main area of concern, the Dewar, will be carried out in a hyperbaric chamber. The control systems will be deemed to have been tested to a satisfactory level during both the shallow water and offshore trials.

\section{ACKNOWLEDGMENTS}

The Technology Strategy Board is a business-led executive non-departmental public body, established by the government. Its mission is to promote and support research into, and development and exploitation of, technology and innovation for the benefit of UK business, in order to increase economic growth and improve the quality of life. It is sponsored by the Department for Innovation, Universities and Skills (DIUS). Please visit www.innovateuk.org for further information.

\section{REFERENCES}

[1] Gores, J.N., Marine Salvage, David \& Charles (Publishing) Limited, 1972, Great Britain, ISBN 071535454 X.

[2] Byrd, R.C., Velazquez, E.R., State of the Art Removing of Large Platforms Located in Deep Water, in the Offshore
Technology Conference, $30^{\text {th }}$ April $-3^{\text {rd }}$ May 2001, Houston, Texas, U.S.A.

[3] Nicholls-Lee, R., Turnock, S.R., Tan, M., McDonald, P.C., Shenoi R.A., Use of cryogenic buoyancy systems for controlled removal of heavy objects from the seabed, in I. 2009, ASME: Honolulu, Hawaii.

[4] Vahterus, (2011), Available at: http://www.vahterus.com/en/front-page (Accessed: 10th January 2011)

[5] Graham Engineering Answers, Heliflow Heat Exchangers, (2011) Available at: http://www.grahammfg.com/index.asp?pageId=28 (Accessed: $10^{\text {th }}$ January 2011) 